\title{
Synthesis and Characterization of $\mathrm{MoS}_{2} / \mathrm{TiO}_{2}$ Nanocomposites for Enhanced Photocatalytic Degradation of Methylene Blue under Sunlight Irradiation
}

\author{
RAMSHA Khan ${ }^{a^{*}}$, ADEEL Riaz $^{\mathrm{b}}$, SOFIA Javed ${ }^{\mathrm{c}}$, RAHIM Jan $^{\mathrm{d}}$ \\ MUHAMMAD Aftab Akram and MOHAMMAD Mujahid ${ }^{\mathrm{f}}$ \\ National University of Sciences and Technology, $\mathrm{H}-12$, Islamabad \\ ${ }^{a}{ }^{*}$ khanramsha70@yahoo.com, badeelriaz03@gmail.com, csofia.javed@scme.nust.edu.pk, \\ drahimjan@scme.nust.edu.pk, eaftabakram@scme.nust.edu.pk, ${ }^{\mathrm{f}} \mathrm{M} . \mathrm{mujahid@scme.nust.edu.pk}$
}

Keywords: Titania, Dichalcogenides, 2D Sheets, Nanocomposites, Sol-Gel Reflux Synthesis, Photodegradation

\begin{abstract}
D nanosheets/ nanoparticles based $\mathrm{MoS}_{2} / \mathrm{TiO}_{2}$ nanocomposites were prepared in different weight compositions which were further employed to investigate photocatalytic degradation of methylene blue. Anatase $\mathrm{TiO}_{2}$ powder was prepared via sol-gel reflux method using titanium tetraisopropoxide as $\mathrm{Ti}$ precursor. $\mathrm{MoS}_{2} / \mathrm{TiO}_{2}$ nanocomposites were prepared by in situ addition of exfoliated $\mathrm{MoS}_{2}$ (2D-nanosheets) in different weight ratios of $0.1 \%, 0.5 \%, 1 \%, 2 \%$ and $5 \%$ in $\mathrm{TiO}_{2}$ sol. Surface morphology, phase analysis, optical properties were studied using SEM, $\mathrm{XRD}$, UV-Vis spectroscopy respectively. SEM results showed that $\mathrm{TiO}_{2}$ nanoparticles were completely adsorbed over the surface of $\mathrm{MoS}_{2}$ sheets as reflux synthesis was employed. Efficient charge carrier separation was achieved which reduced recombination, and hence, enhanced photodegradation of methylene blue was observed. The hetero-structures showed less operation time in sunlight for photodegradation of methylene blue and a highest rate constant was observed by 2 wt.\% loading of $\mathrm{MoS}_{2}$ on $\mathrm{TiO}_{2}$. These composites can also be used commercially as they show promising results.
\end{abstract}

\section{Introduction}

Organic pollutants in groundwater have become a persistent problem, as they affect human beings and other creatures. These organic pollutants can cause eutrophication [1] as they compete for dissolved oxygen present in water. Moreover, the effluents from textile and paper industries which include organic dyes pollute and destroy marine life. In the recent years, many compounds have been synthesized and applied for the degradation of various organic dyes. Many wide-bandgap semiconductors like $\mathrm{ZnO}[2,3]$, $\mathrm{TiO}_{2}[4,5]$, $\mathrm{N}$-doped $\mathrm{TiO}_{2}[6]$ and ferrites[7] have been exploited to degrade these organic compounds for water purification and remediation[8]. Among these semiconductors, anatase $\mathrm{TiO}_{2}$ has been widely utilized as it is anti-corrosive, environmentally friendly, cost-effective and widely available. Rutile $\mathrm{TiO}_{2}$ has a direct band gap of $3.0 \mathrm{eV}$ while anatase $\mathrm{TiO}_{2}$ has an indirect band gap of $3.26 \mathrm{eV}[9]$. As less $\mathrm{e}^{-} / \mathrm{h}^{+}$pair recombination occurs in anatase $\mathrm{TiO}_{2}$, therefore it is the most widely used form. In the presence of UV light electron-hole pair[10] is generated as:

$$
\mathrm{TiO}_{2}+\text { Photons }(\mathrm{h} v) \longrightarrow \mathrm{TiO}_{2}\left(\mathrm{e}^{-}+\mathrm{h}^{+}\right)
$$

Due to the large band gap of $\mathrm{TiO}_{2}$, its many heterostructures have been prepared via doping[11,12] and composites formation $[13,14]$. These structures have been prepared to enhance its photo-generation of electrons and creating a red shift in absorption spectrum[14]. Transition metal dichalcogenides (TMDs) have also been exploited in recent years[15] because of their novel properties. Among TMDs, $\mathrm{MoS}_{2}[16]$ has been exploited recently as it has a graphene-like 2D structure, is chemically stable, and shows excellent photocatalytic properties. It also shows flexible properties for various optoelectronic devices, and it is anti-corrosive so it can be used in aqueous media as well. Bulk $\mathrm{MoS}_{2}$ shows absorption spectrum in the near infra-red region at 1040nm, and 
when it is exfoliated down to monolayer its band gap $\left(\mathrm{E}_{\mathrm{g}}\right)$ increases from $1.2 \mathrm{eV}$ to $1.9 \mathrm{eV}[17]$. The thickness reduction from bulk to nanoscale increases the redox potential of $\mathrm{MoS}_{2}$, and the effective electron transfer takes place from the conduction band of $\mathrm{MoS}_{2}$ to $\mathrm{TiO}_{2}[16,18]$.

In this study, $\mathrm{MoS}_{2} 2 \mathrm{D}$ nanosheets/ anatase $\mathrm{TiO}_{2}$ nanoparticles based nanocomposites[8] were prepared for efficient photocatalytic degradation of organic pollutant. The goal was to prepare nanosized $\mathrm{MoS}_{2}$ sheets with increased band gap so that they can act as a photosensitizer to $\mathrm{TiO}_{2}$ for improved photocatalytic degradation activities[13,19]. The nanocomposites were prepared with different weight ratios of $\mathrm{MoS}_{2}$ sheets, i.e. 0.1 wt. $\%, 0.5$ wt. $\%, 1$ wt. $\%, 2$ wt. $\%$ and 5 wt. $\%$ respectively.

\section{Experimental}

Titanium Tetraisopropoxide (TTIP, Sigma Aldrich) was used as a precursor material to form $\mathrm{TiO}_{2} .11 .6 \mathrm{~g}$ of TTIP was mixed with $2.4 \mathrm{~g}$ of glacial acetic acid $\left(\mathrm{CH}_{3} \mathrm{COOH}\right.$, Merck) for initiating the reaction. $\mathrm{CH}_{3} \mathrm{COOH}$ was added as a proton $\left(\mathrm{H}^{+}\right)$donor and as a chelating agent. The chemicals were mixed for 15 minutes for the complete reaction. After that, $74 \mathrm{ml}$ of water was added to the reaction mixture for hydrolysis of TTIP, and it was stirred for 60 minutes. $0.8 \mathrm{ml}$ of $\mathrm{HNO}_{3}$ was added in the reaction mixture for peptization to prepare $\mathrm{TiO}_{2}$ sol[20]. The reaction mixture was subjected to reflux condensation for 24 hours and was dried at $80{ }^{\circ} \mathrm{C}$ to prepare pure $\mathrm{TiO}_{2}$ powder. 2.3 grams of powder was obtained as result of this synthesis.

For the synthesis of $\mathrm{MoS}_{2}$ nanosheets, $20 \mathrm{mg} / \mathrm{ml}$ of molybdenum (IV) sulphide powder (Sigma Aldrich) was taken in N-methyl-2-pyrrolidone (NMP, Sigma Aldrich). The mixture was sonicated at $1000 \mathrm{rpm}$ for $64 \mathrm{~h}$ that resulted in the exfoliation of bulk $\mathrm{MoS}_{2}$ to $2 \mathrm{D}$ nanosheets. These sheets were added in ratios of $0.1,0.5,1,2$ and $5 \mathrm{wt} . \%$ respectively in $\mathrm{TiO}_{2}$ sol before reflux, respectively. Then the reaction mixture was subjected to reflux condensation for 24 hours. The product obtained was dried at $80^{\circ} \mathrm{C}$ to obtain a greyish powder of the composites and was further annealed in a tube furnace at $450{ }^{\circ} \mathrm{C}$ in inert argon gas atmosphere. Fig. 1(a) shows complete schematics for preparation of nanocomposites.
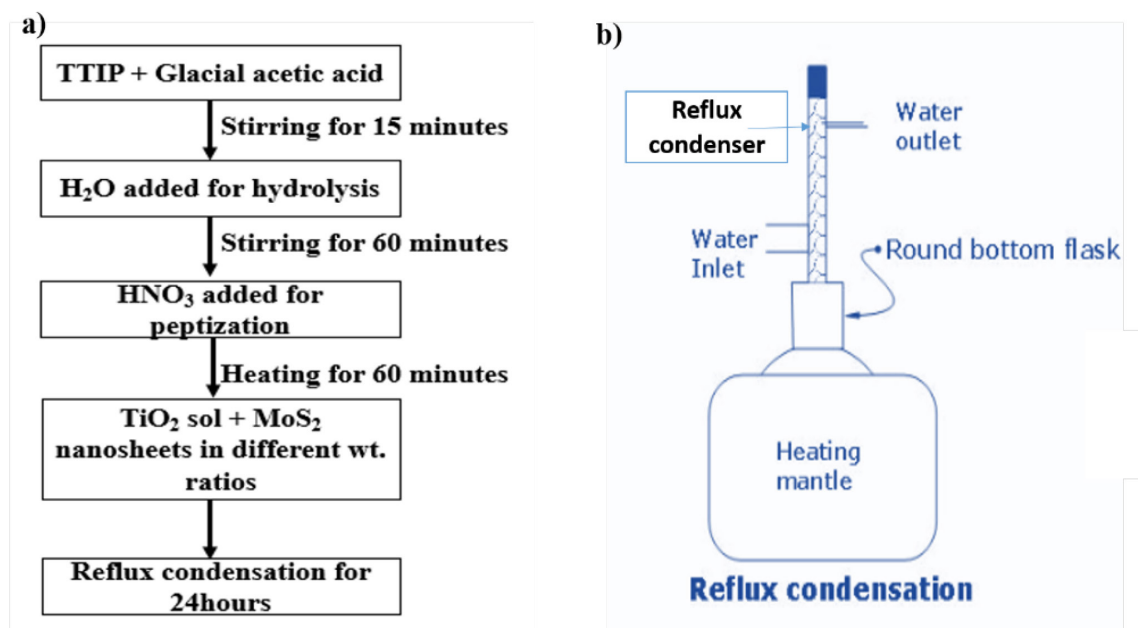

Fig. 1: (a) Schematics of synthesis of $2 \mathrm{D} \mathrm{MoS}_{2}$ nanosheets/ $\mathrm{TiO}_{2} \mathrm{NPs}$ composites (b) Illustration of
apparatus used for reflux condensation

\section{Material Characterization}

Scanning electron microscope (SEM) of samples was carried out by (JOEL JSM-6490A) to analyze structure and morphology of prepared composites. The $\mathrm{MoS}_{2}$ sheets were characterized by Atomic Force Microscope (AFM) using (JEOL-SPM 5200) to determine dimensional aspects. Raman spectroscopy was done by ( $\mu$ Ramboss DONGWOO OPRTON) and for XRD studies, an Xray diffractometer (STOE Stadi MP) was employed at operating voltage and current of $40 \mathrm{kV}$ and $20 \mathrm{~mA}$, respectively. Cu-k $\alpha$ radiation was used as source. UV-Vis was observed by (Jenway 7315 $\mathrm{UV}-\mathrm{Vis}$ spectrometer) to observe optical properties and photodegradation of samples. 


\section{Results and Discussion}

Scanning Electron Microscope (SEM) was used to determine the morphology and lateral dimensions of the $\mathrm{MoS}_{2}$ nanosheets. $\mathrm{MoS}_{2} / \mathrm{TiO}_{2}$ nanocomposites were also analyzed via SEM. Fig. 2(a) shows pure anatase $\mathrm{TiO}_{2} \mathrm{NPs}$ produced as a product of sol-gel reflux synthesis within 24 hours. It can be seen that all the particles have a spherical morphology and particles range from $20 \mathrm{~nm}$ to $35 \mathrm{~nm}$. Fig. 2(b) shows $\mathrm{MoS}_{2}$ nanosheets obtained at $1000 \mathrm{rpm}$ centrifugation speed. Fig. 2(c,d) shows the morphology of the composites. In high resolution images, it can be seen that $\mathrm{TiO}_{2}$ nanoparticles are completely adsorbed over the surface of the $\mathrm{MoS}_{2}$ nanosheets as also shown in Fig. 2(e,f). Therefore, it can be concluded that there is good interfacial bonding between $\mathrm{MoS}_{2} / \mathrm{TiO}_{2}$ which will further aid photodegradation.

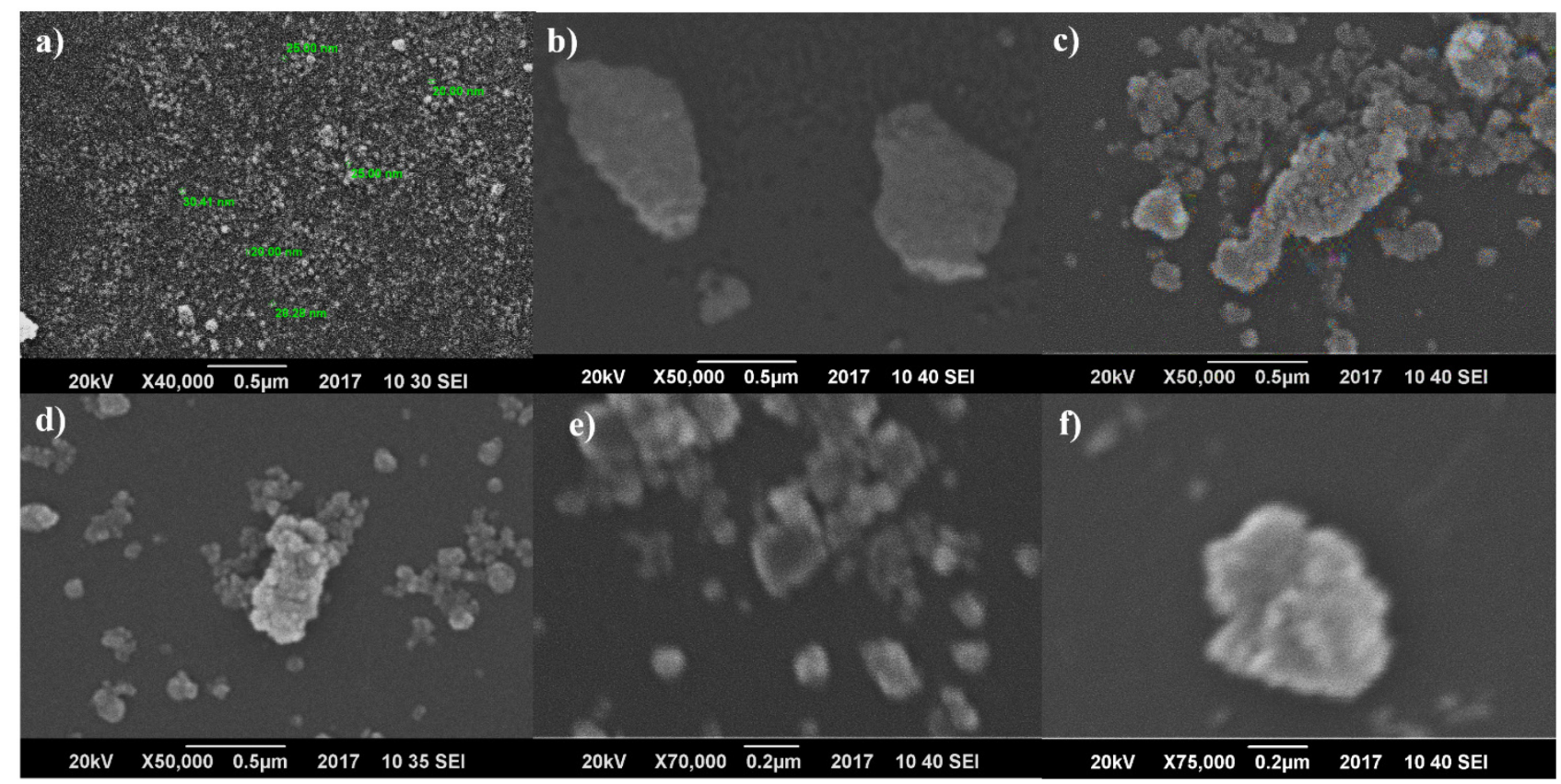

Fig. 2: SEM images of (a) Anatase $\mathrm{TiO}_{2}$ nanoparticles (b) $\mathrm{MoS}_{2}$ flakes centrifuged at $1000 \mathrm{rpm}$ (c,d) $\mathrm{MoS}_{2} / \mathrm{TiO}_{2}$ nanocomposites prepared via sol-gel reflux synthesis (e,f)

High resolution images of composite prepared

Atomic Force Microscope (AFM) was used to determine the thickness of $\mathrm{MoS}_{2}$ sheets. $2 \mathrm{mg}$ of exfoliated $\mathrm{MoS}_{2}$ sheets centrifuged at $1000 \mathrm{rpm}$ were dispersed $10 \mathrm{ml}$ of NMP. It was drop cast over glass slide to analyze the sample. As shown in Fig. 3, it was observed that the sheets were around $0.54 \mathrm{~nm}$ to $2.69 \mathrm{~nm}$ thick which approximately equals to 1-4 layers of $\mathrm{MoS}_{2}$, as its monolayer thickness is $0.65 \mathrm{~nm}[17]$. Therefore, by exfoliation at $1000 \mathrm{rpm}$ the thickness of $\mathrm{MoS}_{2}$ sheets decreased and hence, its band gap increased.

Powdered X-ray Diffraction (PXRD) was done to evaluate the phase of composites. The peaks were observed at $25.06^{\circ}, 37.9^{\circ}, 47.8^{\circ}, 53.77^{\circ}, 54.77^{\circ}, 62.6^{\circ}$ and $76^{\circ}$ which corresponds to tetragonal anatase $\mathrm{TiO}_{2}$ (JCPDS 21-1272). This confirms that only anatase $\mathrm{TiO}_{2}$ is formed as shown in Fig. 3(b) as a result of this synthesis with no extra peak corresponding to rutile or brookite phase. No peak of $\mathrm{MoS}_{2}$ were present due to its relatively very thin layers. UV-Visible spectrum of pure anatase $\mathrm{TiO}_{2}$ and nanocomposites with $\mathrm{MoS}_{2}$ are shown in Fig. 4(a). Samples were prepared by dispersing $2 \mathrm{mg}$ of samples in $10 \mathrm{ml}$ of distilled water. With $\mathrm{MoS}_{2}$ loading, the absorption bands are showing a red shift as shown in zoomed part of Fig. 4(a). This can be attributed to nano-sized $\mathrm{MoS}_{2}$ sheets which provide more active sites and intermediate energy levels for faster chemical activities [21]. And hence, the photocatalytic degradation in the presence of sunlight should be enhanced.

Raman spectroscopy of $\mathrm{MoS}_{2} / \mathrm{TiO}_{2}$ composites was done to determine the coordination of O-TiO. Fig. 4(b) shows the Raman spectra for the composite. $\mathrm{TiO}_{2}$ was also analyzed to ensure the formation of pure anatase phase. All Raman active modes expected by group theory were observed at $120 \mathrm{~cm}^{-1}\left(\mathrm{E}_{\mathrm{g}}\right), 197 \mathrm{~cm}^{-1}\left(\mathrm{E}_{\mathrm{g}}\right), 395 \mathrm{~cm}^{-1}\left(\mathrm{~B}_{1 \mathrm{~g}}\right), 515 \mathrm{~cm}^{-1}\left(\mathrm{~A}_{\mathrm{g}}\right)$ and $635 \mathrm{~cm}^{-1}\left(\mathrm{E}_{\mathrm{g}}\right)$ respectively. 

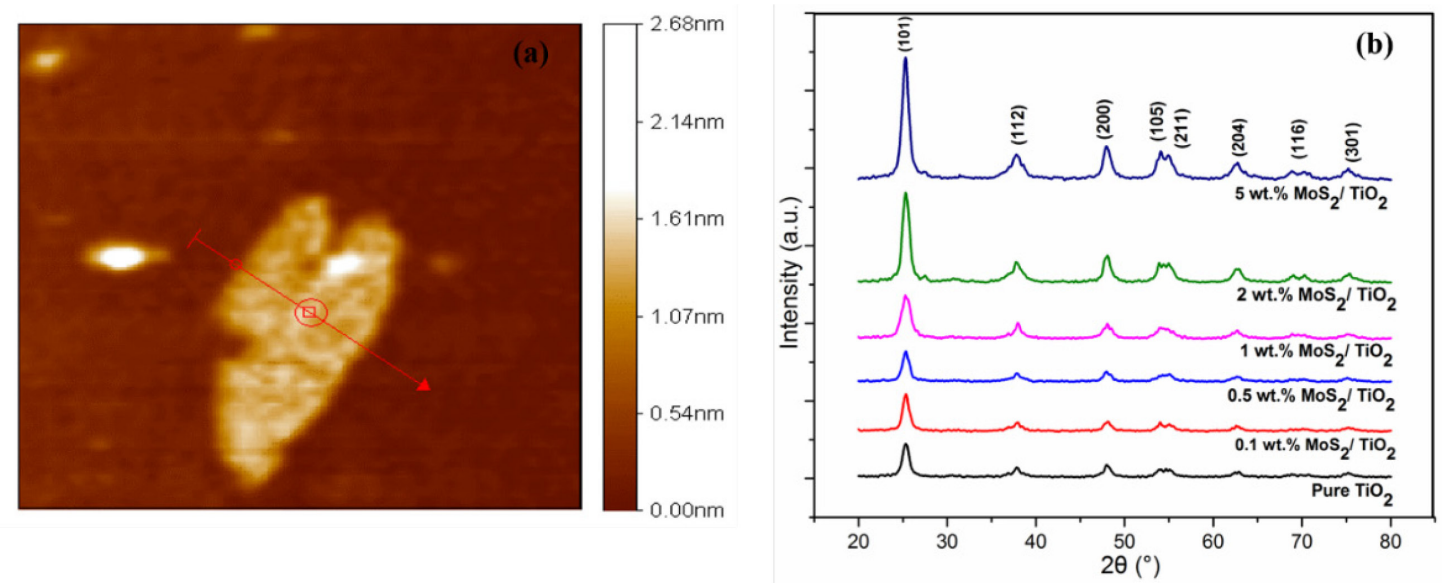

Fig. 3: Thickness profile of $\mathrm{MoS}_{2}$ sheets obtained at $1000 \mathrm{rpm}$ centrifuge speed after exfoliation (b) PXRD spectra of composites prepared with different weight ratios of $\mathrm{MoS}_{2}$

Due to external vibration of anatase structure, $E_{g}$ mode at $140 \mathrm{~cm}^{-1}$ is well resolved. Weak $E_{g}$ mode at $197 \mathrm{~cm}^{-1}$ is also well distinct due to the weak repulsion of oxygen atoms bonded with titanium with the large bond length of $3.04 \AA$. Anatase characteristic peaks were also observed at $395 \mathrm{~cm}^{-1}\left(\mathrm{~B}_{1 \mathrm{~g}}\right)$, and $515 \mathrm{~cm}^{-1}\left(\mathrm{~A}_{1 \mathrm{~g}}\right)$ are due to stretching modes of O-Ti-O and Ti-O bonds [22] respectively. It was seen that pure anatase $\mathrm{TiO}_{2}$ is obtained as result of sol-gel synthesis. Due to the low amount of $\mathrm{MoS}_{2}$ in the samples, no $\mathrm{MoS}_{2}$ peak was observed.
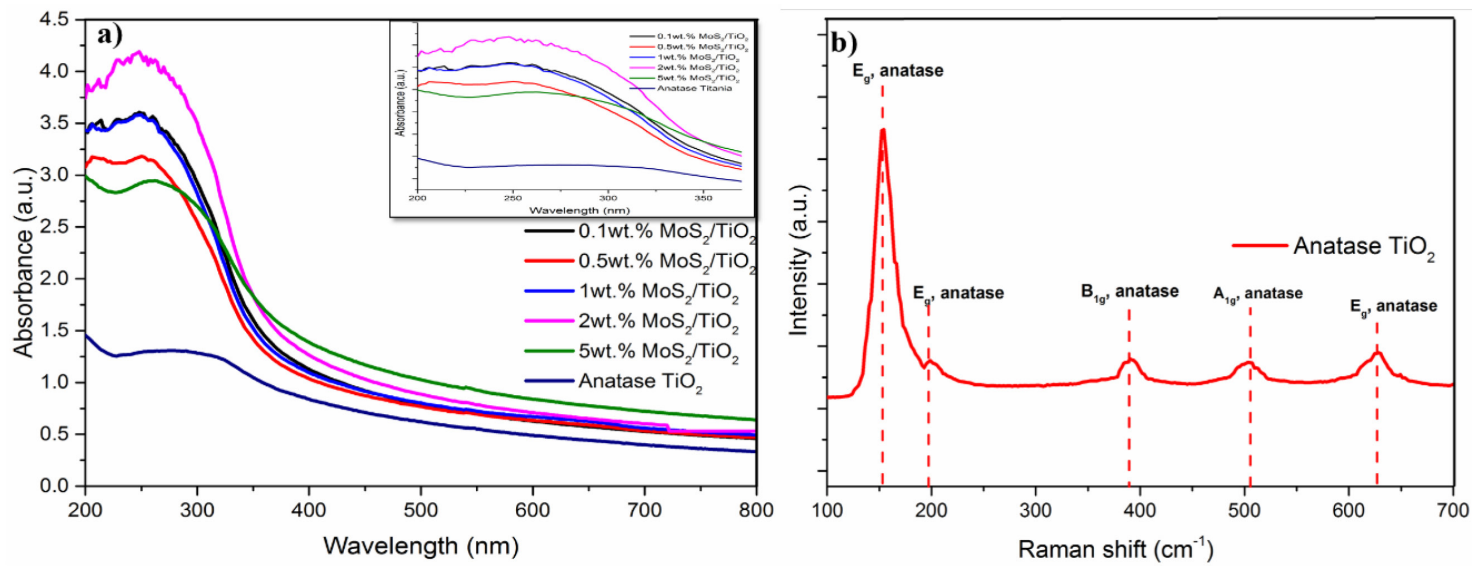

Fig. 4: (a) UV-Vis absorption spectrum of pure anatase $\mathrm{TiO}_{2}$ and prepared photocatalysts (b) Raman Spectrum of pure anatase $\mathrm{TiO}_{2} \mathrm{NPs}$

The photocatalytic degradation of methylene blue (MB) dye was evaluated under sunlight irradiation. MB dye was used as it is a hazardous organic water pollutant. Also, it is used in dyes, cosmetics, paper industries and given off in water which affects marine life [23,24]. 10mg of MB dye was added in $1 \mathrm{~L}$ of distilled water. $50 \mathrm{ml}$ of this solution was used in each beaker and $5 \mathrm{mg}$ of photocatalyst was added to it. Before irradiation, the samples were added to MB dye solution and sonicated for 30 minutes in the dark for uniform dispersion of photocatalysts. Fig. 5(a) shows that when samples were irradiated in the presence of sunlight, MB dye started to degrade. This happened due to efficient interfacial bonding between nanosheets and nanoparticles. The degradation was highest for $2 \mathrm{wt} . \% \mathrm{MoS}_{2} / \mathrm{TiO}_{2}$ nanocomposites, and complete degradation was achieved in just 5 hours. The reaction rate constant of the composites increased up to $2 \mathrm{wt} \%$ of $\mathrm{MoS}_{2}$ addition and then decreased, as $\mathrm{MoS}_{2}$ sheets start to agglomerate causing the recombination rate of the photo-generated electrons and holes to increase. The degradation rate and irradiation time follow the first-order reaction kinetics[13,25]. This can be expressed as $\ln \left(\mathrm{C} / \mathrm{C}_{0}\right)=-\mathrm{kt}$, where $\mathrm{k}$ is rate constant and $\mathrm{C}$ and $\mathrm{C}_{0}$ are the initial and final concentration of methylene blue respectively, and ' $\mathrm{k}$ ' is the apparent reaction rate constant. This is elaborated graphically in figure 5(b). Fig, 5(c) shows the rate constants which various photocatalysts depicted. Table 1 shows that reaction rate constant reached an optimum value of $0.559\left(\mathrm{hr}^{-1}\right)$ by $2 \mathrm{wt} . \%$ addition and then decreased by further addition of $\mathrm{MoS}_{2}$ sheets. 

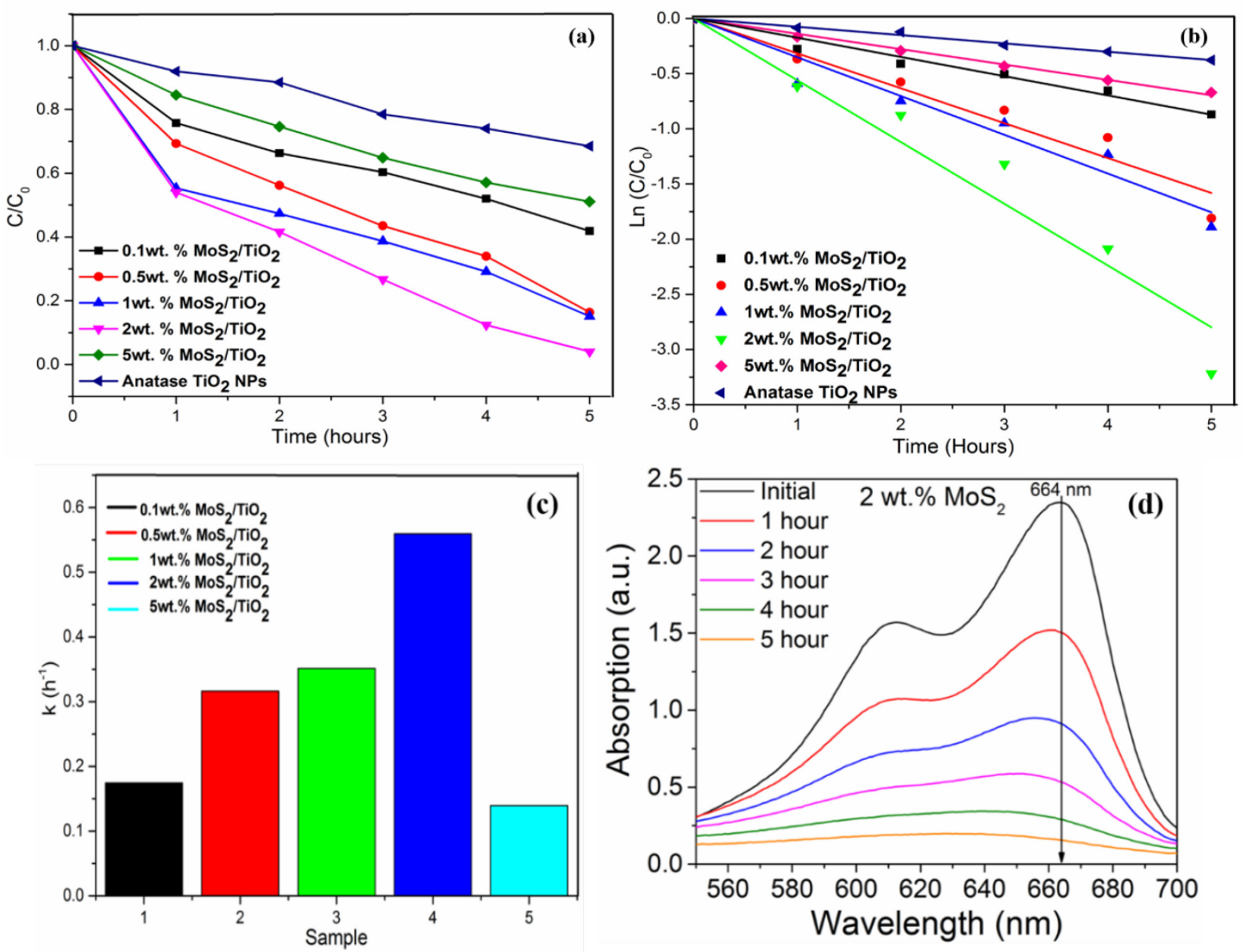

Fig. 5: (a) $\mathrm{C} / \mathrm{C}_{0}$ curve concerning time for the dye degradation via different nanocomposite catalysts (b) $\mathrm{Ln}\left(\mathrm{C} / \mathrm{C}_{0}\right)$ curve to elucidate rate constants of reaction (c) Rate constants observed via prepared nanocomposites (d) Degradation of $\mathrm{MB}$ dye by 2 wt. $\% \mathrm{MoS}_{2} / \mathrm{TiO}_{2}$ nanocomposites

Fig. 6 shows photocatalytic degradation mechanism of nanocomposites prepared. In case of pure anatase $\mathrm{TiO}_{2}$, degradation occurs solely due to electrons and holes production in its valence band. In case of nanocomposites, when sunlight is irradiated on photocatalyst $\mathrm{e}^{-} / \mathrm{h}^{+}$production takes place in $\mathrm{MoS}_{2}$ as exfoliated $\mathrm{MoS}_{2}$ has high redox potential level [25].

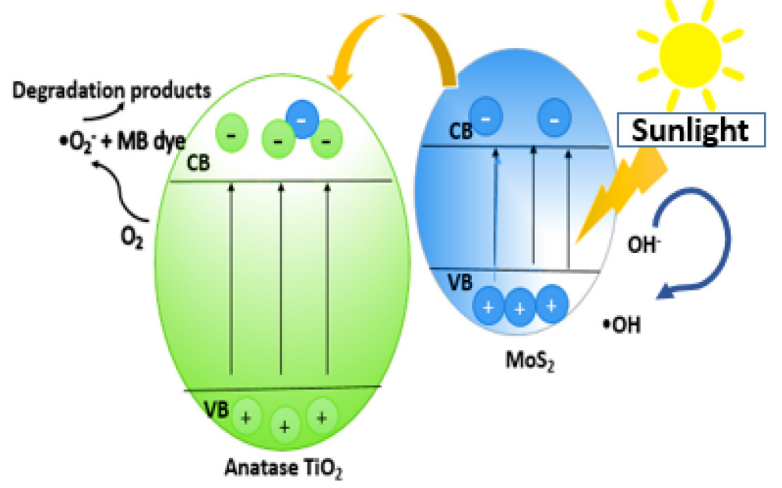

Fig. 6: Photodegradation mechanism as shown by the photocatalysts

Electrons move from its valence to conduction band and are further transferred to the conduction band of $\mathrm{TiO}_{2}$. These holes react with $-\mathrm{OH}$ ions to form peroxide $(\mathrm{OH} \bullet)$ radicals. Also, electrons react with oxygen $\left(\mathrm{O}_{2}\right)$ to form superoxide $\left(\cdot \mathrm{O}_{2}{ }^{-}\right)$radicals $[26,27]$. These species formed then degrade organic pollutants like methylene blue. 
Table 1: Rate constants ' $k_{\text {app' }}$ and band gaps for various photocatalysts prepared are shown

\begin{tabular}{|c|c|c|}
\hline Samples & $\begin{array}{l}\text { Rate constant } \\
\text { 'k' }\left(\mathbf{h r} \mathbf{r}^{-1}\right)\end{array}$ & $\begin{array}{l}\text { Band Gap } \\
(\mathrm{eV})\end{array}$ \\
\hline $\begin{array}{c}\text { Pure } \mathrm{TiO}_{2} \text { as-prepared } \\
\text { NPs }\end{array}$ & 0.07 & 3.35 \\
\hline 0.1wt. $\% \mathrm{MoS}_{2} / \mathrm{TiO}_{2}$ & 0.174 & 3.08 \\
\hline 0.5wt. $\% \mathrm{MoS}_{2} / \mathrm{TiO}_{2}$ & 0.316 & 3.06 \\
\hline 1wt. $\% \mathrm{MoS}_{2} / \mathrm{TiO}_{2}$ & 0.351 & 3.02 \\
\hline 2wt. $\% \mathrm{MoS}_{2} / \mathrm{TiO}_{2}$ & 0.559 & 2.95 \\
\hline 5wt. $\% \mathrm{MoS}_{2} / \mathrm{TiO}_{2}$ & 0.139 & 2.76 \\
\hline
\end{tabular}

\section{Conclusions}

$\mathrm{TiO}_{2}$ was synthesized via facile sol-gel reflux method, and nanocomposites with $\mathrm{MoS}_{2}$ were prepared by in-situ addition of exfoliated $\mathrm{MoS}_{2}$ nanosheets in different weight ratios. XRD and Raman spectrum confirmed the formation of a pure anatase phase of $\mathrm{TiO}_{2}$. SEM images revealed that the $\mathrm{TiO}_{2}$ nanoparticles were completely adsorbed over $\mathrm{MoS}_{2}$ ts. AFM analysis showed that the exfoliated $\mathrm{MoS}_{2}$ were only 1-4 layers thick. The prepared nanocomposites showed increased photogenerated electron-hole pair production and improved charge transfer as more active edges were present in $\mathrm{MoS}_{2}$ due to exfoliation, so an enhanced photocatalytic activity was observed. UV-Vis results showed that loading of exfoliated $\mathrm{MoS}_{2}$ leads to an increase in the photodegradation activity due to increase the charge carrier separation in the visible light. The reaction rate constant gradually increased and reached to $0.559 \mathrm{~h}^{-1}$ which was optimum at $2 \mathrm{wt} . \%$ addition of $\mathrm{MoS}_{2}$ and then decreased due to agglomeration of the sheets and fast recombination rate of the charge carriers.

\section{References}

[1]V.H. Smith, G.D. Tilman, J.C. Nekola, Eutrophication: impacts of excess nutrient inputs on freshwater , marine, and terrestrial ecosystems, Envir. Pollu., 100 (1999) 179-196.

[2]Y.H. Tong, Y.C. Liu, S.X. Lu, L. Dong, S.J. Chen, Z.Y. Xiao, The optical properties of ZnO nanoparticles capped with polyvinyl butyral, J. Sol-Gel Sci. Technol., 30 (2004) 157-161.

[3]N.M. Bahadur, T. Furusawa, M. Sato, F. Kurayama, N. Suzuki, Rapid synthesis, characterization and optical properties of $\mathrm{TiO} 2$ coated $\mathrm{ZnO}$ nanocomposite particles by a novel microwave irradiation method, Mater. Res. Bull., 45 (2010) 1383-1388.

[4]C. Zhao, J. Zhang, Y. Hu, N. Robertson, P.A. Hu, D. Child, D. Gibson, Y.Q. Fu, In-situ microfluidic controlled, low temperature hydrothermal growth of nanoflakes for dye-sensitized solar cells., Sci. Rep., 5 (2015) 17750-17759.

[5]M. Liu, L. Piao, W. Wang, Hierarchical $\mathrm{TiO}_{2}$ spheres: Facile fabrication and enhanced photocatalysis, Rare Met. 30 (2011) 153-156.

[6]J.Y. Park, C.S. Kim, K. Okuyama, H.M. Lee, H.D. Jang, S.E. Lee, T.O. Kim, Copper and nitrogen doping on $\mathrm{TiO} 2$ photoelectrodes and their functions in dye-sensitized solar cells, J. Pow. Sour., 306 (2016) 764-771.

[7]W. Luo, L. Zhu, N. Wang, H. Tang, M. Cao, Y. She, Efficient removal of organic pollutants with magnetic Nanoscaled $\mathrm{BiFeO}(3)$ as a reusable heterogeneous fenton-like catalyst. TL - 44, Environ. Sci. Technol., 44 (2010) 1786-1791.

[8]M. Pumera, Nanohybrids of Two-Dimensional Transition Metal Dichalcogenides and Titanium Dioxide for Photocatalytic Applications, Chem. - A Eur. J., 23 (2017) 323-341. 
[9]U. Diebold, Structure and properties of $\mathrm{TiO}_{2}$ surfaces: A brief review, Appl. Phys. A Mater. Sci. Process., 76 (2003) 681-687.

[10] J.-Y. Park, C. Lee, K.-W. Jung, D. Jung, Structure Related Photocatalytic Properties of TiO2, Bull. Korean Chem. Soc., 30 (2009) 402-404.

[11] Y. Duan, N. Fu, Q. Liu, Y. Fang, X. Zhou, J. Zhang, and Y. Lin, Sn-Doped TiO2 Photoanode for Dye-Sensitized Solar Cells, J. Phys.Chem. C, 116 (2012) 8888-8893.

[12] P. Xiang, W. Ma, T. Xiao, L. Jiang, X. Tan, T. Shu, Ta-doped hierarchical TiO2 spheres for dye-sensitized solar cells, J. All. Compd., 656 (2016) 45-50..

[13] W.P. Zhang, X.Y. Xiao, L.L. Zheng, C.X. Wan, Fabrication of TiO2/MoS2 Composite Photocatalyst and Its Photocatalytic Mechanism for Degradation of Methyl Orange under Visible Light, Can. J. Chem. Eng., 93 (2015) 1594-1602.

[14] G. Lui, J.Y. Liao, A.S. Duan, Z.S. Zhang, M. Fowler, A.P. Yu, Graphene-wrapped hierarchical $\mathrm{TiO} 2$ nanoflower composites with enhanced photocatalytic performance, J. Mater. Chem. A., 1 (2013) 12255-12262.

[15] M. Chhowalla, H.S. Shin, G. Eda, L. Li, K.P. Loh, H. Zhang, The chemistry of twodimensional layered transition metal dichalcogenide nanosheets, Nat. Publ. Gr. 5 (2013) 263-275.

[16] G. Cunningham, M. Lotya, C.S. Cucinotta, S. Sanvito, S.D. Bergin, R. Menzel, M.S.P. Shaffer, J.N. Coleman, Solvent exfoliation of transition metal dichalcogenides: Dispersibility of exfoliated nanosheets varies only weakly between compounds, ACS Nano., 6 (2012) 3468-3480.

[17] X. Li, H. Zhu, ScienceDirect Two-dimensional MoS 2: Properties, preparation, and applications, J. Materiomi., 1 (2015) 110-118.

[18] W. Ho, J.C. Yu, J. Lin, J. Yu, P. Li, Preparation and Photocatalytic Behavior of MoS 2 and WS 2 Nanocluster Sensitized $\mathrm{TiO}_{2}$, Langmuir. 20 (2004) 5865-5869.

[19] Q. Xiang, J. Yu, M. Jaroniec, Synergetic effect of MoS 2 and graphene as cocatalysts for enhanced photocatalytic H 2 production activity of TiO 2 nanoparticles, J. Am. Chem. Soc., 134 (2012) 6575-6578.

[20] S. Javed, M. Mujahid, M. Islam, U. Manzoor, Morphological effects of reflux condensation on nanocrystalline anatase gel and thin films, Mater. Chem. Phys., 132 (2012) 509-514.

[21] X. Lu, G. Wang, T. Zhai, M. Yu, J. Gan, Y. Tong, Y. Li, Hydrogenated TiO 2 nanotube arrays for supercapacitors, Nano Lett., 12 (2012) 1690-1696.

[22] W.F. Zhang, Y.L. He, M.S. Zhang, Z. Yin, Q. Chen, Raman scattering study on anatase $\mathrm{TiO}_{2}$ nanocrystals, J. Phys. D. Appl. Phys., 33 (2000) 912-916.

[23] S. Lakshmi, R. Renganathan, S. Fujita, Study on TiO2-mediated photocatalytic degradation of methylene blue, J. Photochem. Photobiol. A Chem., 88 (1995) 163-167.

[24] W.H. Wei C., Zhang, F. Hu F., Feng, C., Ozonation in water treatment: the generation, basic properties of ozone and its practical application, Rev. Chem. Eng., 167 (2016) 2191-235.

[25] I. Tacchini, E. Terrado, A. Anson, M.T. Martinez, Preparation of a TiO2-MoS2 nanoparticlebased composite by solvothermal method with enhanced photoactivity for the degradation of organic molecules in water under UV light, Micro Nano Lett., 6 (2011) 932-936.

[26] K.H. Hu, X.G. Hu, Y.F. Xu, J.D. Sun, Synthesis of nano-MoS2/TiO2 composite and its catalytic degradation effect on methyl orange, J. Mater. Sci., 45 (2010) 2640-2648.

[27] H. Nguyen, T. Phung, V.N.K. Tran, L.T. Nguyen, L. Kieu, T. Phan, P.A. Duong, H. Vu, T. Le, Investigating Visible-Photocatalytic Activity of MoS 2 / TiO 2 Heterostructure Thin Films at Various MoS 2 Deposition Times, J. Nanomat., 11 (2017) 12-18. 